\title{
FABRICATION AND CHARACTERIZATION OF ALUMINUM
}

\section{BASED COMPOSITE MATERIAL}

\section{RADHAKRISHNA, N. GOPIKRISHNA, P. NAGABHARAM \& DHEERAJ JOSHI}

Assistant Professor in the Department of Mechanical Engineering,

$S$ R Engineering College, Warangal, Telangana, India

\section{ABSTRACT}

Composite materials are basically applied to the structures, bridges, operational parts and buildings, such composites from the pure metals. ex: aluminum, which have less hardness comparatively and good tensile properties. In order to minimize and overcome this problem, in general, different materials at various percentages to the pure metals were added and their properties have been investigated. Thus, better hardness can be achieved in earlier studies. But, in this study, The materials like aluminum (7075-T6), the glass powder and the resin of different sizes are taken for making and preparation of the composite materials. Aluminum, used as a base metal and by varying the percentages of the known additives, a composite can be made and thus, to the made specimen material properties have been studied. KEYWORDS: Hardness, Izod Test, Tensile Test \& The Composite Material

Received: Sep 15, 2018; Accepted: Oct 06, 2018; Published: Oct 26, 2018; Paper Id.: IJMPERDDEC201819

\section{INTRODUCTION}

Composites with an aluminum metal alloy matrix is a group of materials that are due to their quantifiable properties are many and more frequently applied in the modern engineering constructions. Composite materials are basically applied to the structures, bridges, operational parts and buildings, such composites from the pure metals. ex: aluminum, which have less hardness comparatively and good tensile properties. In order to minimize and overcome this problem, engineers concentrate on making of composite materials.

L. A. Dobrzański, A. Włodarczyk, M. Adamiak et al., [1] made investigations on composite materials of EN AW-Al Cu4Mg1(A) an aluminum alloy which is reinforced with the $\mathrm{Ti}(\mathrm{C}, \mathrm{N})$ particles with the weight ratios of a 5, 10, and $15 \%$ are presented. S. Vorozhtsov, D. Eskin3, A. Vorozhtsov, S. Kulkov et al., [2] made observations on electrical and physico-mechanical properties of a aluminum-based composite material with the carbon nanoparticles katica miloš, ivica jurić, pero škorput, et al., [3] made investigations on Aluminum-Based composite materials that are in construction of the transport means. The role of engineering materials in the development of modern technology need not be emphasized. It is the materials through which a designer puts forward his ideas in to practice. R.Ramanujam et al., [4] effort has been made to prepare the hybrid aluminum metal matrix composite that is to study its machining and expected mechanical properties. Preparation of hybrid aluminium metal matrix composite is made by reinforcing the Silicon carbide and the Titanium di boride. Keshavamurthy $\mathrm{R}$ and Sadananda Mageri et al., [5] studied about Al7075-TiB2 in-situ composite, processed by stir casting technique using commercially available $\mathrm{Al}-10 \% \mathrm{Ti}$ and $\mathrm{Al}-3 \% \mathrm{Br}$ master alloys. Both matrix alloy and composite were subjected to microstructure analysis, micro hardness test, grain size studies and tensile test. Microstructure shows fairly uniform 
distribution of TiB2 particles in matrix alloy. Average grain size of the composite was lower than unreinforced alloy. Micro hardness, yield strength and ultimate tensile strength of Al7075-TiB2 composite, is high when compared with the unreinforced alloy. Mahendra boopathi, k.p. arulshri N. Iyandurai, et al[6]. Experimented to Development of hybrid metal matrix composites has become an important area of research interest in materials science. Rajesh A M and Mohammed Kaleemulla et al., [7] Experimental investigations made on aluminum alloy and studied on mechanical behavior of the aluminium alloy metal matrix composites [8] P. Nagabharam et al., fabricated and characterized Aluminum Based Composite Material and tested the specimens. [9] P. NAGABHARAM, L. RADHAKRISHNA and DHEERAJ JOSHI et. Al., investigated mechanical properties of aluminium based composite material. [10] J. Manoj kumar and N. Gopikrishna et. al.,made comparative studies on mechanical characteristics of granulated blast furnace slag and flyash reinforced aluminium composites

\section{EXPERIMENTATION}

\section{Sample Making}

Firstly selected materials should be taken as per the required quantity that is needed for preparation of composite specimen. A pattern (wood) is prepared as per dimensions $210 \times 12 \times 7 \mathrm{~mm}$, as aluminum being the base metal, Aluminum alloy (7075-T6) (as depicted in figure 1) is melted until it reaches melting point temperature i.e., it gets converted into molten state. Now other two materials, powder (as shown in figure 2) and hardener (as depicted in figure 3) being added which are of known quantities, into the molten aluminum metal. They were mixed thoroughly until proper mixing of materials take place. It is then poured into the mould cavity and allowed to cool at room temperature until it gets solidified completely. It is removed by opening two halves of the die and to the required specimen is what collected.

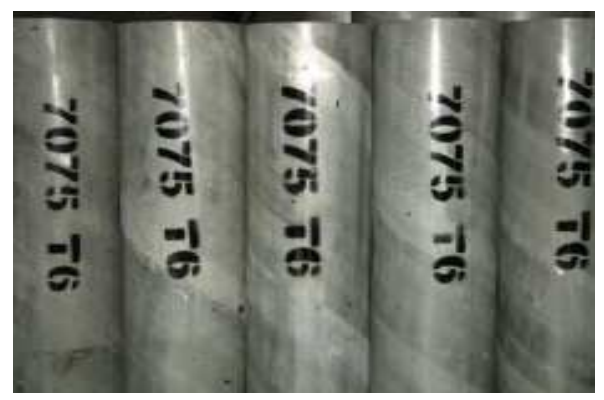

Figure 1: Al 7075 T 6

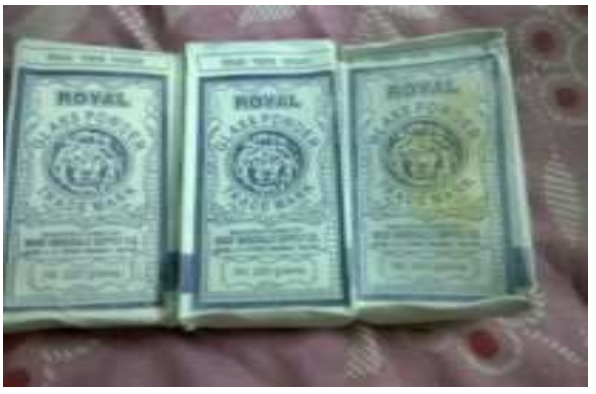

Figure 2: Powder

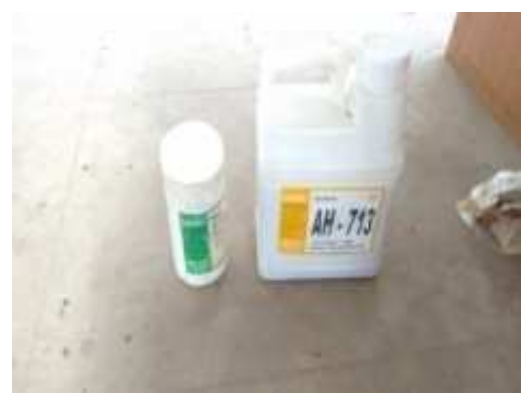

Figure 3: Hardener

\section{Casting Process}

Pattern is prepared, according to the ASTM Standards, dimensions and shape which are shown as figure 4 and 5 


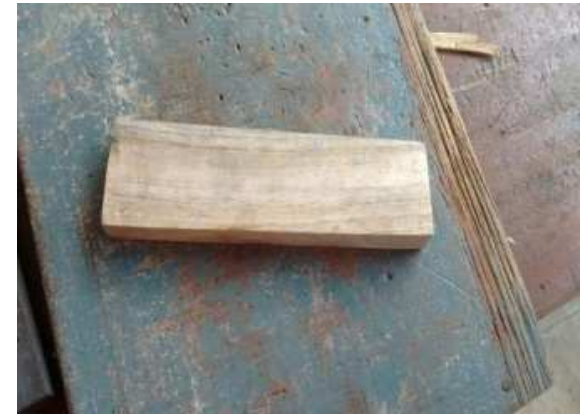

Figure 4: Wood

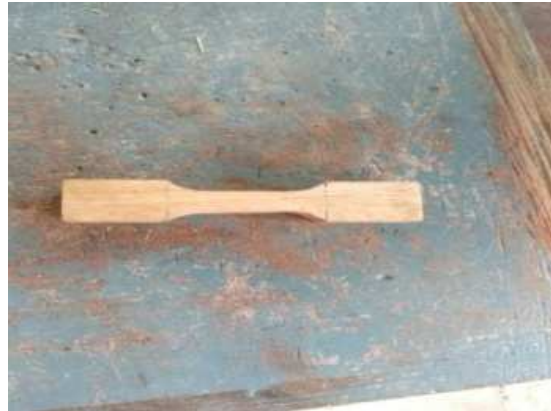

Figure 5: Pattern

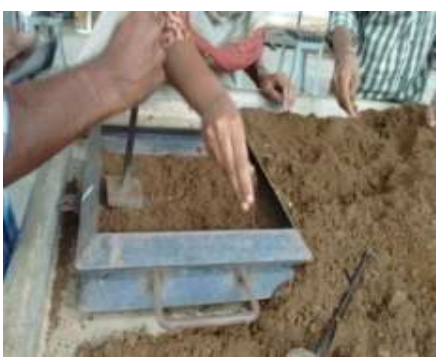

Figure 6: Molding

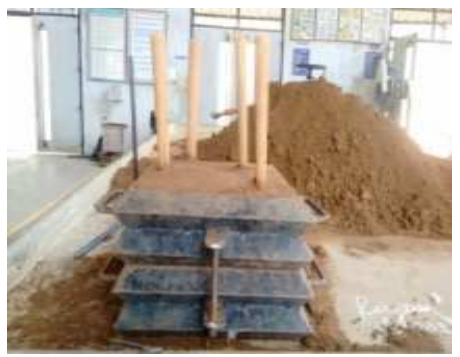

Figure 7: Prepared Cavity

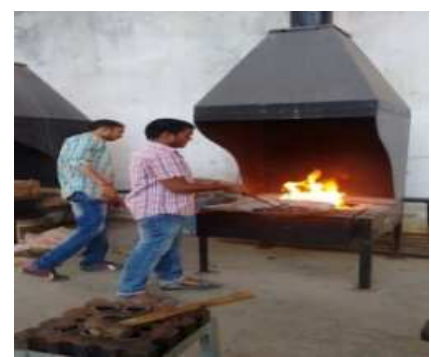

Figure 8: Melting

Then pattern is placed in the drag (have depicted in figures 6 and 7) and parting sand is sprinkled and ramming is done.

After completing this, cope is placed on the drag and also runner and riser are placed and again ramming is done.

Now, the cope is removed and gate cutting, sprue basin are made.

Runner, riser are removed and again cope is placed on the drag.

Aluminum alloy and glass powder mixture is melted until it reaches the liquid state, during melting as shown in figure 8 .

The molten metal is then poured into the mould cavity which is coated with the resin and hardener mixture and it is allowed to cool and solidify.

After sometime the material is removed and machining is done to get good surface finish.

In this way, composite material is prepared.

Once the preparation of the composite material is over, the following tests are conducted and the results are compared with the individual properties.

\section{Tests}

\section{Tensile Test}

In this test, a sample is subjected to the tension till the breaking point. The properties, which are directly measured via tensile test, are maximum elongation, ultimate tensile strength and reduction in area. A tensile test is also known as tension test is a mechanical test that can be performed on materials. Test is relatively inexpensive, simple and fully standardized. 
From these measurements the following properties can also be determined: Young's modulus, Poisson's ratio, yield strength, and strain-hardening characteristics.

A tensile specimen (as shown in figure 9) is a standardized sample cross-section. It has two shoulders and a section in between. The shoulders are large so they can be readily gripped, whereas the section has a smaller cross-section so that the deformation and failure can occur in this area.

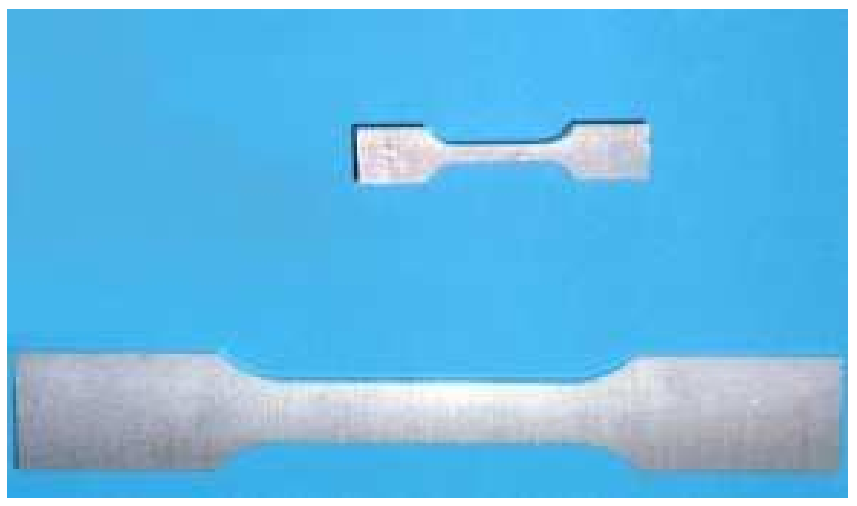

Figure 9: Tensile Specimen

\section{RESULTS}

Table 1: Results

\begin{tabular}{|l|l|l|}
\hline \multicolumn{1}{|c|}{ Property } & $\begin{array}{c}\text { Composite } \\
\text { Material with } \\
\text { K-47 Hardener }\end{array}$ & $\begin{array}{c}\text { Composite } \\
\text { Material with } \\
\text { K-6 Hardener }\end{array}$ \\
\hline Impact strength & 6 Joules & 196 Joules \\
\hline Hardness & 43.67 & 34.2 \\
\hline Tensile strength & $76.351 \mathrm{Mpa}$ & \\
\hline
\end{tabular}
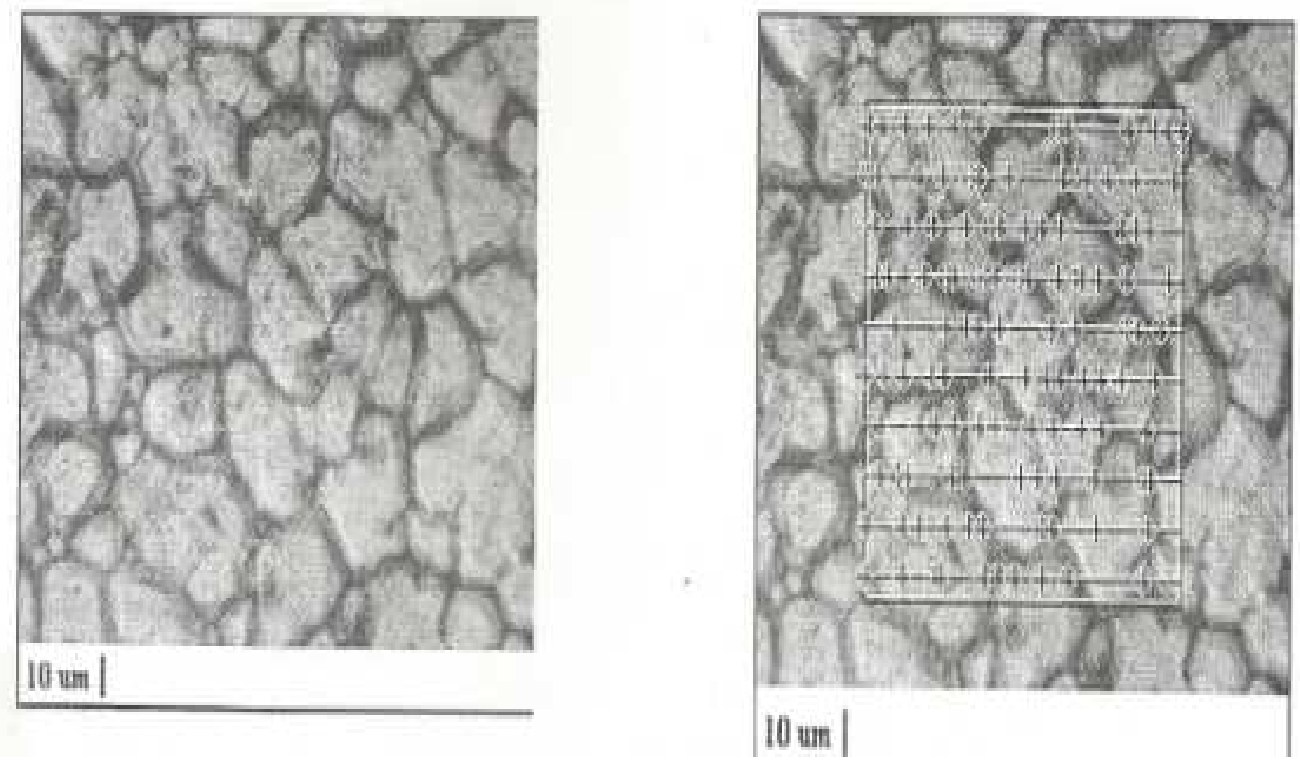

Figure 10: Microstructure for Composite Material with K-47 Hardener

The given sample has grain size according to ASTM E112, the number is 5 . 


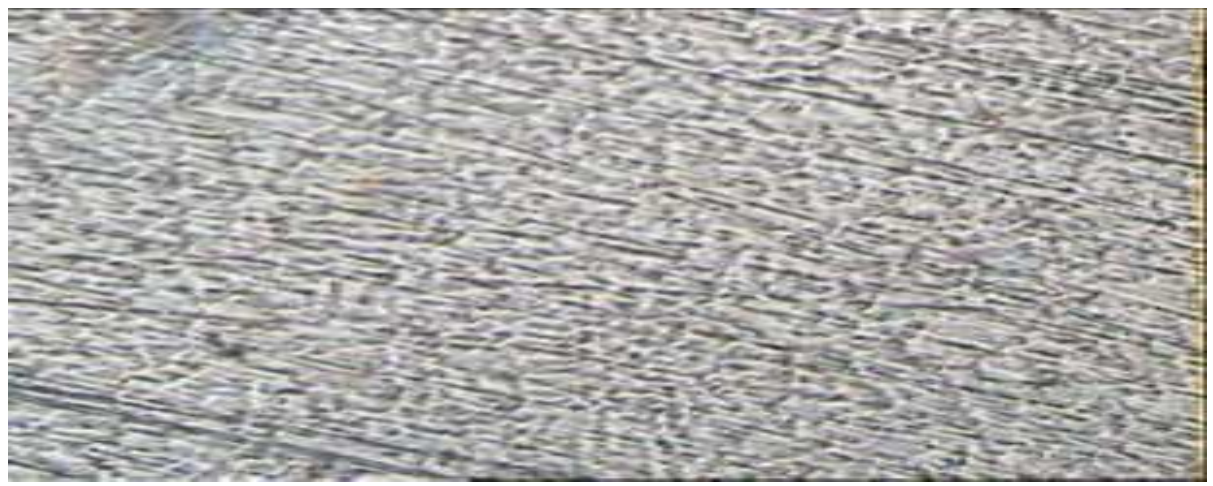

Figure 11: Microstructure for Composite Material with K-6 Hardener

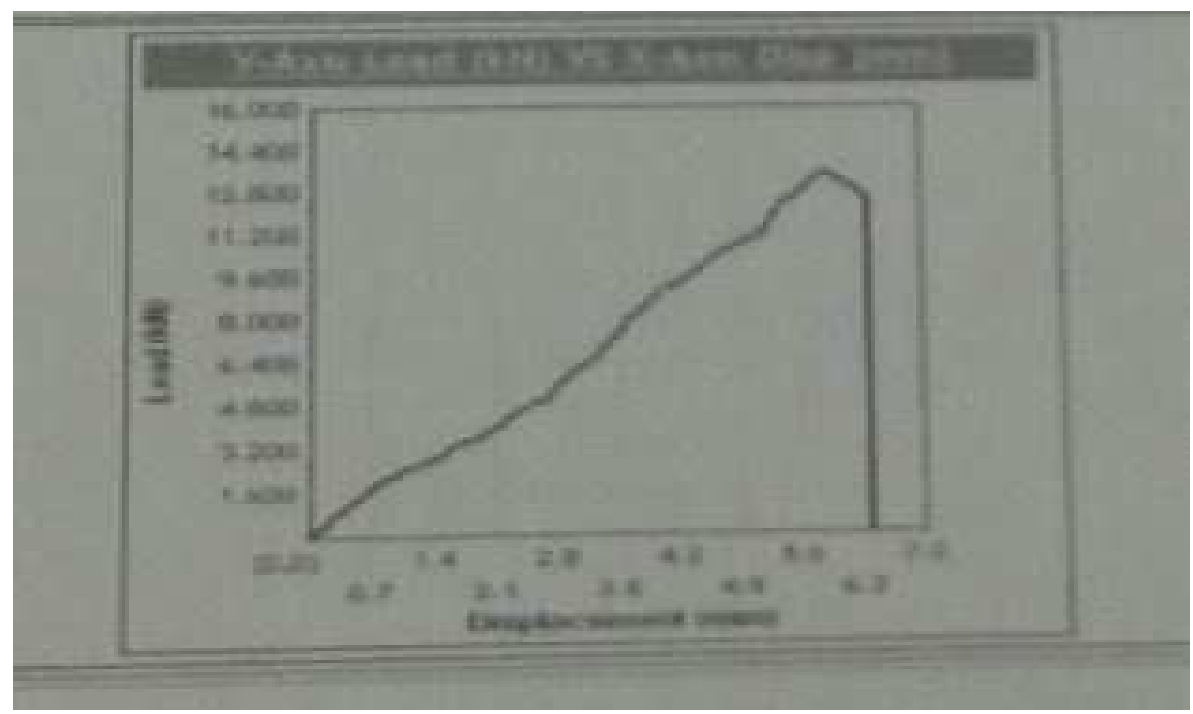

Figure 12: Graph for Tensile Test with K-47 Hardener

\section{CONCLUSIONS}

We have studied the properties (as tabulated in Table 1) of prepared aluminum alloy and prepared the composite material by adding glass powder, resin and hardeners K-47,K-6. It has been noticed

It is observed that the hardness is more for K-47 hardener when compared to K-6 hardener.

Also, the grain size of the composite material improved when compared with aluminum alloy.

\section{REFERENCES}

1. Dobrzański L.A., Włodarczyk A., Adamiak M.: 12th Scientific International Conference "Achievements in Mechanical.and Materials Engineering” AMME’2003, Politechnika Śląska,Gliwice-Zakopane, 2003, p. 297 (in Polish)

2. S.A. Vorozhtsov, S.P. Buyakova, S.N. Kulkov. Izvestiya Vyssh. Uchebn. Zaved. Poroshk Metall. Mnogofunktsion. Pokryt., 2011, no. 1, pp. 52-57.

3. K. Miloš, I. Jurić, P. Škorput: Aluminium-Based Composite Materials in Construction of Transport Means , Promet Traffic\&Transportation, Vol. 23, 2011, No. 2, 87-96

4. S. JohnyJames, K.Venkatesan, P.Kuppan, R.Ramanujam "Hybrid Aluminium Metal Matrix Composite Reinforced with SiC and $\mathrm{TiB}_{2}$ " - Procedia Engineering Volume 97, 2014, Pages 1018-1026 
5. Keshavamurthy R. and Sadananda Mageri, et.al: Microstructure and Mechanical Properties of Al7075-TiB2 in-situ composite, Research Journal of Material Sciences, Vol. 1(10), (6-10), 2013.

6. Mahendra boopathi, k.p. arulshri N. Iyandurai, Evaluation of mechanical properties of aluminium alloy 2024 reinforced with silicon carbide and fly ash metal matrix composites, American journal of applied sciences, 10(2013),219-229

7. Rajesh A M and Mohammed Kaleemulla, "Experimental investigations on mechanical behavior of aluminium metal matrix composites" - Materials Science and Engineering 149 (2016) 012121 doi:10.1088/1757-899X/149/1/012121|pp : 1-12

8. P. Nagabharam "FABRICATION, CHARACTERIZATION AND TESTING OF ALUMINUM BASED COMPOSITE MATERIAL” 'International Journal of Mechanical Engineering and Technology (IJMET) Volume 8, Issue 11, November 2017, pp. 494-499

9. P. NAGABHARAM*1, L. RADHAKRISHNA*2, DHEERAJ JOSHI*3 “MECHANICAL PROPERTIES OF ALUMINUM BASED COMPOSITE MATERIALS” International Journal of Engineering Research|Vol.3., Issue.6., 2015 (Nov.-Dec.,) | pp 242-245

10.J. Manoj kumar and N. Gopikrishna “ COMPARATIVE STUDIES ON MECHANICAL CHARACTERISTICS OF GRANULATED BLAST FURNACE SLAG AND FLYASH REINFORCED ALUMINIUM COMPOSITES” International Journal of Mechanical Engineering and Technology (IJMET) Volume 8, Issue 11, November 2017, pp. 277 - 284 